\title{
INSPIRE Hackathons and SmartAfriHub - Roadmap for Addressing the Agriculture Data Challenges in Africa
}

Karel Charvát ${ }^{1}$, Akaninyene Obot $^{2}$, Stephen Kalyesubula ${ }^{3}$, Foteini Zampati ${ }^{4}$, Tuula Löytty ${ }^{5}$, Hana Kubíčková1, Petr Uhlíŕ ${ }^{6}$, František Zadražil ${ }^{7}$

${ }^{1}$ Plan4all z.s., Horní Bř́íza, Czech Republic

${ }^{2}$ Department of Agricultural Economics and Extension, Nnamdi Azikiwe University, Awka, Nigeria

${ }^{3}$ Makerere University, Kampala, Uganda

${ }^{4}$ GODAN, Montreal, Canada

${ }^{5}$ Smart \& Lean Hub Oy, Lahti, Finland

${ }^{6}$ Czech Center for Science and Society, Prague, Czech Republic

${ }^{7}$ Wirelessinfo, Litovel, Czech Republic

\begin{abstract}
Digital farming holds enormous potential for agricultural development, and giving farmers the tools to boost productivity and profitability. Although the benefits of digitalization are numerous, farmers feel they are not the ones benefiting from the value of data collected on their farms. Several issues were identified as factors restricting farmers from benefiting from data-driven agriculture. From the farmers' perspective, there is a distinct lack of awareness of the issues surrounding farm data, and the complexity of these issues. This feeds into the imbalance that exists between individual farmers and larger agribusinesses wherein the former lack enough resources to address and analyse the significance of data, and so cannot take advantage of the value in it. There is also limited legislation for the generation, flow, exchange and use of data; where legislation does exist, it is not well understood by farmer organisations. From a policy perspective, moreover, there is very little guidance as to which agricultural data can be considered personal data, and therefore protected by privacy laws. This paper analyses the interactions and effects of the 5 Concepts: Open Agricultural Data, Open-Source Software, Citizen Science, privacy and legal and ethical issues that are assumed to advance the digitalization of African Food System (AFS and the enabling Digital Innovation Hub (DIH) - SmartAfriHub (https://www.smartafrihub.com/home).
\end{abstract}

\section{Keywords}

Africa Smart Agriculture, Open Data, Open-Source Software, Citizen Science.

Charvát, K., Obot, A., Kalyesubula, S., Zampati, F., Löytty, T., Kubíčková, H., Uhlír, P. and Zadražil, F. (2021) "INSPIRE Hackathons and SmartAfriHub - Roadmap for Addressing the Agriculture Data Challenges in Africa“, AGRIS on-line Papers in Economics and Informatics, Vol. 13, No. 4, pp. 33-48. ISSN 1804-1930. DOI 10.7160/aol.2021.130404.

\section{Introduction}

The African Development Bank released a report in April 2020 which stated that Africa has 65\% of the world's remaining uncultivated arable land, an abundance of freshwater and about 300 days of sunshine each year. More than $60 \%$ of Africa's working population is engaged in agriculture, and the soil across most of the continent is rich and fertile. Yet despite that potential, the continent as a whole continues to import much of its food ( $\$ 64.5$ billion in 2017) and many regions continue to suffer annual famines with around five million Africans dying every year from hunger and over a quarter of the population classified as severely food insecure in 2016 (African Development Bank, 2020). The problems of food security are growing with growing population and also with climatic changes (Heidhues et al., 2004; Ngcamu, B. S., and Chari, F., 2020; Rosina et al., 2019; Govender et al., 2017; Thompson et al., 2010). The food security is influencing different age groups (Mkhize, M. and Sibanda, M., 2020; Bishwajit et al., 2020). These problems are increasing now in relation to COVID 19 pandemy (Paganini et al., 2020).

To increase efficiency and productivity and thus 
hopefully reduce hunger and reliance on imports, many African countries are now looking for new technologies (Jha et al., 2020) to data collection and analysis for solutions and creating a new demand and market by doing so (Ahmed et al., 2009). Many now see the use of data identifying the areas offering the most lucrative prospects as the way to move forward. Coupled with simpler smartphones to be used in situ, data scientists can analyze data from satellite imagery and records of climate and weather patterns to help focus on those initially promising areas (Henriques and Kock, 2012; Batchelor et al., 2014).

A "Zero Hunger", one of the 17 Sustainable Development Goals (Nilsson et al., 2016) that were adopted by all 191 United Nations Member States, is a goal that aims at ending hunger (Mbow, 2020), achieving food security and improved nutrition and promoting sustainable agriculture by 2030 . African Food System (AFS) is a central driver of sustainable development. AFS link diverse interlocked issues and uncertainty incorporating social economy (poverty, accessibility, equity), security, technology (innovation), nutrition (health and welfare), local/traditional cuisine preservation (culture at large), rural desertification vs urbanization, employment, circularity and sustainability, climate action (de-carbonization, emissions, bio economy, blue growth), and more (Mbow, 2020; FCRN, 2015).

AFS currently are a cornerstone of human development recently referred to as "the global standard for sustainability" and framed in "The European Green Deal" that encompasses global trade, working life, schooling spheres, public health, and companies and consumers links across all sectors of the AFS (Communication from The Commission to The European Parliament, 2019).

The United Nations Food and Agriculture Organisation (UN-FAO) conceptual approach to structured sustainable AFS outlined by the food system wheel framework calls for the activation and engagement of all actors and stakeholders of the food system (FAO, 2018).

Digitization is under way with a variety of benefits regarding AFS needs, from production to waste management, also incorporating food security, ecosystem services, economy and social inclusion (Ndung'u and Signé, 2020). AFS are propelled by the emerging possibilities of Information and Communication Technologies (ICT) technologies that are turning AFS into big data systems which are significantly and increasingly impacting the food supply chain (Lynd and Woods, 2011) at a global scale.

The ability to learn from evidence in the real-time via data collection can make sustainable processes that are responsive, proactive and predictive. Intelligent usage of data enhances the ability to achieve a highperformance level regarding quality, delivery, cost, safety and environmental sustainability in the food value chain. The analysis of complex and dynamic AFS leads to rapidly expanding data requirements. (May et al., 2007)

There are a number of challenges that Africa's agricultural sector faces (Middelberg, 2013). As far as development of uncultivated land is concerned, many areas have poor or no transport links. There may be little in the way of communications, little credit to buy the machinery and seed stock needed to cultivate the land, issues with property rights, endemic corruption at local and national levels, a lack of access to technology, and various other issues. Another major problem that faces the sector, and also another that technology may offer a solution to, is that many African agricultural products are subject to the overuse of pesticides (or the use of banned pesticides). This means that they do not pass the stringent standards of target markets such as the European Union (AfricaMe-Team, 2020).

These days, public authorities as well as other institutions and organizations produce large amounts of data and information. The Open Government Data (OGD) initiative (Bello et al., 2016), a set of policies that promotes transparency, accountability, collaboration and participation by making data accessible to all, has emerged (Afful-Dadzie, E. and Afful-Dadzie, A., 2017). However, there are countries where there are barriers to adoption of this initiative: "While much of the research has remained confined to unraveling the theoretical and conceptual dimensions of OGD, empirical investigations are visibly lacking, especially in African context. Using a qualitative research methodology, they analyzed the responses received from relevant stakeholdersrepresentatives from public and private sectorregarding their views about the OGD initiative in Tanzania. The findings showed that the OGD initiative in Tanzania is in an emerging stage and there are barriers (organizational, social, legal and technical) toward instituting a robust OGD initiative in the country. Further, we find that there is inertia among the governments in terms of publishing data sets." (Donald Shao and Saxena, 2019). 
According to Afful-Dadzie, E. and Afful-Dadzie, A. (2017), OGD continues to receive considerable traction around the world. In particular, there have been a growing number of OGD establishments in the developed world, sparking expectations of similar trends in growing democracies. In their result using conjoint analysis, the result indicates that media practitioners ascribe to the selected set of OGD attributes in anticipation of a more functional OGD in their respective countries. Using conjoint analysis, the result indicates that media practitioners put a premium on 'metadata' and 'data format' respectively in order of importance. Results from the review also reveal that features of current OGD web portals in Africa are not consistent with the desired preferences of users.

A number of other issues identified were factors restricting farmers from equally benefiting from using and sharing of agricultural data. From the farmers' perspective, there is a distinct lack of awareness of the issues surrounding data, and the complexity of these issues. This feeds into the imbalance that exists between individual farmers and larger agribusinesses wherein the former lack sufficient resources to address and analyze the significance of data, and so cannot take advantage of the value in it. There is also limited legislation for the generation, flow, exchange and use of data; where legislation does exist, it is not well understood by farmer organizations. From a policy perspective, moreover, there is very little guidance as to which agricultural data can be considered personal data, and therefore protected by privacy laws (Addison, 2018).

One of the more important pillars of the digital transformation effort is the activity to develop a network of Digital Innovation Hubs (DIHs) (Rissola and Sörvik, 2018; Klerkx, 2019). DIHs could be defined as non-profit co-working spaces where common users, technologists, scientists, hackers, web developers share their ideas and transform them into real values.

The aim of our research was to use hackathon to build community of African Stakeholders, explore the concepts of Open Agricultural Data, Open-Source Software and Hardware, Citizen Science i.e., multi-actor, participatory and volunteer cooperation, privacy and legal and ethical issues, and the enabling Digital Innovation Hub (DIH) named SmartAfriHub, and foresight their effect on AFS developers and practitioners' readiness to uptake digital- and sustainability driven solutions.

\section{Materials and methods}

\section{The INSPIRE Hackathon Concept}

Main instruments for collecting information for this study were two INSPIRE Hackathons organised in 2019 and 2020 as Nairobi (Nairobi INSPIRE Hackathon, 2019) and Kampala Hackathons (Anand, 2020), (Kampala INSPIRE Hackathon, 2020). The INSPIRE hackathon concept was born as a means to support sustainability and implementation of results of the European Commission Research Framework Program FP7 and H2020 (Bye et al., 2018), (Bye et al., 2017), (Kollwitz, 2019). The initial idea was mainly to focus on the sustainability of the datasets Open Land Use (Mildorf et al., 2014), Smart Point of Interest (Čerba and Mildorf, 2016) and Open Transport Map (Jedlička et al., 2016) coming from SDI4Apps (Charvat et al., 2014a), Open Transport Net (Jedlička et al., 2015) and FOODIE (Charvat et al., 2014b) projects. In cooperation with citizens observatories projects CITI-SENSE, CobWeb (Higgins et al., 2016), Ground Truth 2.0, LandSense (Moorthy et al., 2017). We started to build the concept of combination Voluntary Geographic Data Initiatives (Harris et al., 2012), (Charvát et al., 2011), (Charvát et al., 2013) and citizens observatories (Higgins et al., 2016).

The intention was also to bring together different project communities to facilitate the transfer of technology and knowledge between projects and, where appropriate, to organizations and companies (Directive 2007/2/Ec, 2007). Since 2016, over fifteen hackathons have been organized by the Plan4All association. The network of supporters, co-organisers, and active hackers is steadily growing. Open data and open source, interoperability, support for Copernicus, INSPIRE and GEO (2020 - 2022 GEO Work Programme, 2020) remain the common themes of the events, despite variations in areas of expertise, perspectives, and technical abilities. The Hackathons themselves spark many interesting ideas, with the results from one often forming the basis for the next hackathon. INSPIRE events are open to everyone interested, serving as a platform for international expert collaboration, training, and capacity building (Bye et al., 2018).

INSPIRE hackathons in Africa, (Nairobi (2019) and Kampala (2020) provide the research setting - Living Lab to assess the 5 Concepts and their interplay. The concept of the INSPIRE Hackathon 
(Figure 1) differs from traditional hackathons in that it is not just a multi-day event, but it is a continuous process that has been designed to be effective using the results obtained from previous hackathons. This means that challenges are defined to follow the results of previous hackathons with the aim at enriching those previous innovation actions. INSPIRE Hackathons are several months lasting virtual events. The overall INSPIRE hackathon process consists of 5 main stages, whereby data is being collected during the so called "hacking" stage and made available during the post-hackathon stage.

The goal of the Kampala and Nairobi INSPIRE Hackathon was to build and strengthen the partnership between various EU projects and African communities. African hackathons attracted nearly 500 participants representing 70 countries. Nairobi and Kampala hackathons were organized around 19 challenge teams. Precipitated by the COVID-19 pandemic, the Kampala INSPIRE Hackathon was organised as a fully virtual event which succeeded well. These hackathons formed a unique social space that is multi-actor, open and participatory. The participation is based on ethical and volunteer cooperation to solve challenges on digital transformation in the field of Food Systems. The series of 2 hackathons shape a Living Lab that provides a testbed to analyse 5 Concepts: Open Data, Open Source Software, Citizen Science i.e. multi-actor, participatory and volunteer cooperation, privacy and legal and ethical issues, and the enabling Digital Innovation Hub (DIH) named SmartAfriHub.

\section{Open Agriculture Data}

Open Agricultural data - data that anyone can find, access, use or share, reuse - can help shape solutions by enabling more efficient and effective decision-making at multiple levels across various agricultural food systems, fostering innovation via new services and data driven applications, and driving organizational change through transparency (Charvát et al., 2014b; Musker and Schaap, 2018; Clark et al., 2020; Kamilaris et al., 2017). For Open Agricultural data to act as a road map for digital transformation in Africa, it must be FAIR (Findable, Accessible, Interoperable and Reusable) (Wong et al., 2019). A wide range of specific off-farm and on-farm Agricultural Data is needed across the food value chain to help farmers and actors in making data-driven operational decisions to optimize yield and boost revenue while minimizing expenses, chances of crop failure, and environmental impact.

However, the majority of smallholder farmers in Africa are often the one who are significantly more affected by unfair data sharing, packaging, unequal or insufficient key information and data (McCullough et al., 2008). While this gap in information is most acutely and directly felt in terms of farm activities, markets and price, it is also equally pervasive in the planning, production and postharvest management aspects of smallholder agriculture. All these factors have pushed their lives with agriculture as an occupation of gamble especially for key questions like; What produce can I grow where I live? When should I

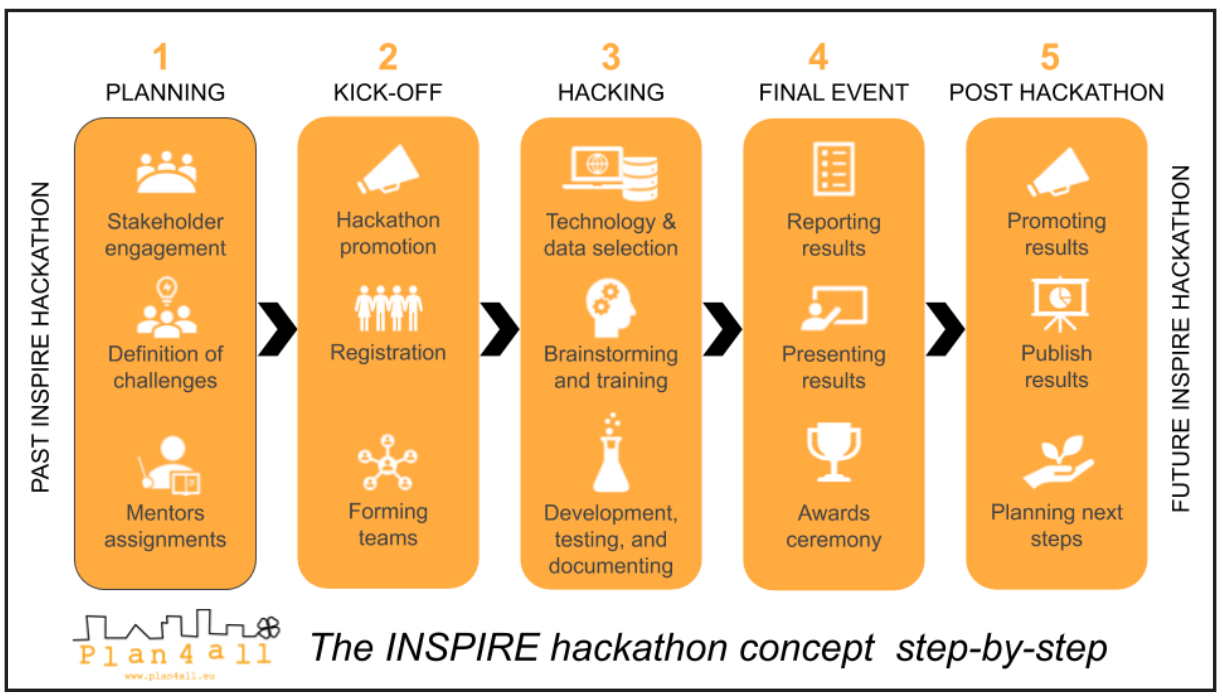

Source: own processing

Figure 1: The general concept of the INSPIRE Hackathon: Showing how events feed into each other as part of an ongoing process that defines the INSPIRE concept. 
sow/plant/harvest/market it? How should I sow/ plant/ harvest/market it? How to minimize food waste? among many. An example of an SMS crop seasonal forecast alert extracted from the Uganda Weather Information Dissemination System (WIDS) as of $23^{\text {rd }}$ July 2019 for Mukono district presents advice on the appropriate farming activities they can carry out in the January-March season. However, the information is poorly arranged and too abstract for the farmers to unpack.

\section{Data Privacy and legal and ethical issues}

Smart farming contributes to exponential income growth, enhanced decision making, better services and products, as well as greater agricultural efficiency, productivity and profitability. However, it is well known that whoever controls farm data has the power and means to create the most relevant agricultural services and products, which in turn also capture insights for the development of more lucrative innovations.

Nowadays, numerous agricultural technology providers are entering the market, focusing on aggregating farmers' data. But many farmers, especially smallholders, do not benefit from the sharing and exchange of this data, which leaves them feeling disempowered. There are two key challenges that need to be overcome for smallholders to truly benefit: first, they need to be provided with better access to relevant data and services; second, they need greater awareness on the topic of personal data to ensure that any information they share does not weaken their position.

While laws and regulations that govern personal data (such as The European General Data Protection Regulation or GDPR) are becoming increasingly common, there is a lack of legislation covering the collection, sharing and use of data in agriculture. A lack of transparency around issues of data ownership, better control of access to and use of data, data rights, privacy, security and whether farm data should be considered 'personal' or not, are some of the data challenges faced by all agricultural stakeholders, but farmers in particular. Moreover, data transactions are currently governed by contracts and licensing agreements, but the terms of these contracts and agreements are complex, which leaves smallholder farmers with very little negotiating power and it is obvious that a lack of trust dominates these relationships.

Up until now, ethical considerations were often side-lined because gathering more data was seen as necessary, and concerns about how data might be abused or misused were only subsequently considered. However, with the increase of big data in smart farming, it is more essential than ever to focus on the ethical aspects of data governance (access, control, consent) and practices. This will provide valuable insights into how data is being collected and used, and for what purposes, how to bridge the digital divide, and how to create transparency in order to build trust between stakeholders.

To ensure that the benefits of the digital revolution in agriculture reach everyone involved, especially farmers, there is a need to identify sustainable ways to support data sharing among various stakeholders (Zampati, 2019).

\section{Citizen Science to support multi-actor and participatory approach}

Citizen Science (Khaldoon et al., 2020), (DehnenSchmutz et al., 2016), (Ryan et al., 2018) is the collection and analysis of data relating to the natural world by members of the general public, typically as part of a collaborative project with professional scientists. It is the practice of public participation and collaboration in scientific research to increase scientific knowledge. Through citizen science as SmartAfriHub framework, innovators analyze problems, generate ideas, build prototypes, test and share working prototypes that contribute to data collection, use, monitoring and evaluation of processes and programs. Usually, this participation is done as an unpaid volunteer.

\section{Open-Source Software and Hardware}

Open-Source Software (Tonnang et al., 2020; Charvát, 2009; Charvát and Krivanek, 2010) is the type of computer software in which the source code is released under a license in which the copyright holder grants users the rights to use, study, change and distribute the software to anyone and for any purpose, it refers to something people can modify and share because its design is publicly accessible. Examples of Open source software packages include; QGIS, GIS, Open streetmap, Python etc. These could be used to design data driven mobile apps like ChatBots, Crop monitoring softwares using geospatial datasets etc. Open source software and hardware are the driving forces of the SmarAfriHub towards creating data driven solutions for the farmers. 


\section{WhatsUp as potential tools for African Citizens Science}

According to the Global Digital Report, there were 192 million social media users in Africa in 2018 . Nearly $90 \%$ of those users were mobileonly. The most popular application in Africa was WhatsApp. WhatsApp provides access to online communication particularly to those rural area inhabitants where there is no traditional telephone infrastructure. For many, WhatsApp is the first app they download into their mobile and the one they use most.

INSPIRE Hackathon is digital-oriented. In the European context, the hackathon organisation team uses the newest and advanced technologies e.g. webinars, platforms, video conferences to facilitate communication. In the African context, the hackathon participants' communication was possible almost only by using Whatsapp.

WhatsApp group SmartAfriHub has reached 50 members' level, mainly agricultural experts from Africa. During the INSPIRE Hackathons, the facilitated and free-format WhatsApp communication formed the glue which kept participants along the process. Already in early stages in addition to hackathon team mentors, several active colleagues from different African countries took responsibility to initiate, administer and facilitate the communication and debate. It was remarkable that the atmosphere of communication was respectful and polite aiming to share knowledge and find solutions to problems of African agriculture.

The broad view on Citizens Science concept includes e.g. generation of any theory or hypothesis, research, scientific data collection, and/or data analysis in which the public (individuals or communities) participates. African Citizens Science movements' first step is to connect people with each other, facilitate their communication, and empower them to work together for Africa society and for themselves

\section{SmartAgriHub Digital Innovation Hub}

Building on and complementing the various national initiatives for digitising domains, the European Commission acts to trigger further investments in the digitisation of domains and support the creation of better framework conditions for the digital transformation. One of the most important pillars of the digital transformation effort is the activity to develop a network of Digital Innovation Hubs (DIH).

The INSPIRE hackathon can be generally defined as a collaborative event for developers, researchers, designers and others interested in open data, volunteered geographic information and citizen observatories. In the SmartAfriHub, INSPIRE hackathons are the tools used with the idea to bring together different project communities to facilitate transfer of technology and knowledge between the projects, and eventually also to organizations and companies.

SmartAfriHub is a Digital Innovation Hub that connects people to digital information and services in Africa. DIH integrates African agriculture and climate community members, and beyond, to the knowledge bases e.g., Blog, Forum, Science Shop, WIKI. DIH provides different types of Open Source Softwares and demo applications, where farmers, developers and researchers can cooperate, test different API for new solutions and also provide common experiments upon geospatial information and agriculture. The SmartAgriHub is developed in cooperation with 3 European companies - Plan4All, Wirelessinfo, Club of Ossiach - with the intention of supporting and furthering smart and sustainable agriculture in Africa. We reused the concept, which was already validated in some European projects (Ulman et al., 2020).

\section{Results and discussion}

\section{Can Hackathon stimulate cooperation of African} stakeholders?

Both African INSPIRE Hackathons introduced concepts of Citizen Science and multi-actor and participatory approaches. The INSPIRE Hackathon teams were formed by a multi-actor and participatory approach on a voluntary basis. Teams encompass different disciplines, experiences, nationalities and skills that complement each other and enrich the communication and extend the potential solutions. The innovation pattern of hackathon teams applied a multi-actor and participatory approach. All phases of the innovation pattern; ideation, building, piloting and reflecting, were carried out together, aimed at a maximum participation by using available digital and collaborative tools e.g. teleconferences, social media (e.g., Facebook, Linkedin, Twitter and WhatsApp) and shared work spaces in cloud services. SmartAfriHub is the center of communication.

Regarding smart and sustainable agriculture development the key factors were; the data, knowhow and skills, and applications to form data to information. All three are needed. Regarding 
data, the procedure can be either top-down i.e., Open Data provided by government, authorities or companies, or bottom-up which means that smallscale data sets can be collected by regular citizens, researchers, practitioners, and share the data set via the internet. The latter approach was applied often in the concept of Citizen Science. INSPIRE Hackathon team members were encouraged to look into and carry out data collection in order to test how to collect data and how to exploit the collected data at various Open Source Softwares. Though there was not much available data, the participants assigned were able to gather data on country based for analysis (Kampala INSPIRE Hackathon, 2020).

The most important result is that we demonstrate sustainability of such an approach and also the large interest of African communities about such types of Hackathons. It was demonstrated by 3 facts:

1. From 230 participants on the first Hackathon 170 participated also in the second year.

2. After Kampala Hackathon, was organised COVID 19 INSPIRE Hackathon (COVID-19 INSPIRE Hackathon, 2020), which was primarily not focused on Africa, but there were two teams (namely Developing a blockchain technology to enhance tracking and tracing of food items throughout the value chain to ensure food security in Africa and Digitalization of indigenous knowledge in African agriculture for fostering food security) organised by African communities participating in previous Hackathons and there teams were managed by African mentors and reached excellent results.

3. African participants of Nairobi Hackathon organised a self-sustainable and open WhatsUp community of 50 members. It operates continuously with a support of 5 administrators and several active members. The members use it as a channel to exchange knowledge, advertise events, connect to experts and reach out African smart agriculture practitioners.

What are the main problems of African Agriculture in this period and What are solutions, for which African communities are looking for? How could sustainability of African Agriculture be supported?

During Hackathons were discussed important challenges for African Agriculture and on the base of community feedback in different teams we select a number of priority topics. It was done through questionnaires, face to face communication and also during discussion on the final ceremony on the Nairobi Hackathon. The main priorities of African communities for sustainable agriculture and food security were detected: Needs to build Rural commodity exchange hub. Production and productivity - To tackle this issue, we really need to restart almost everything, African agriculture needs to change. And with the issue of climate change this has to be taken as a priority, Market failure - The responsibilities are shared, at the farmers' level, buyers' level and institutions. It is important to build trust among all stakeholders, High transaction cost - the main issue here is information asymmetry. It is important to make a platform that will give correct information about what is happening. All stakeholders need to know exact information of what farmers are producing in a given village in Africa. The platform needs to inform farmers about the need on the market, It is important to build sampling plots from different agro-climatic zones in Africa and monitor their growth using earth observation techniques together with ancillary data like weather data and biophysical data, There is a need for establishing crop growth scenarios under different weather events that could help in projecting future yields which is very critical in the planning operations and budgeting by state agencies and county governments, To build systems for prediction of disease susceptibility of crops using the temporal crop dynamics from earth observation data. Using historical data of crop disease and connecting them with features extracted from earth observation data for generating alert of probable crop disease, To provide a combination of agent-based models of human activities and how these contribute to food (in) security and a dynamic change in the environment as captured by big earth observation data, To develop accurate monitoring crop phenology to aid the application of farm inputs like fertilizers, irrigation and farm management, To provide assessment of hydrological flows through a combination of field observations and output from satellite image analysis workflows, Provide augmenting weather and climate monitoring through the use of affordable in-situ weather sensors and remote sensed weather estimates

Some topics coming from the Nairobi Hackathon were already implemented during Kampala Hackathon and during COVID 19 INSPIRE Hackathon.

A key problem for extension and adoption of ICT 
services in Agriculture supporting its sustainability was identified as a financial problem and it was discussed that there is a need to identify financial sources for building African ICT for Agriculture infrastructure.

What is the situation with Ethic, Data Privacy, Open Data and Open Software and Hardware, and how can African community benefit from them?

This topic was discussed mainly during Kampala Hackathon as part of Challenge 9: Ethical and legal aspects of open data affecting farmers. As results of the work and discussion were recognised next facts: There is an emerging need to enhance the ethical and legal frameworks in agriculture. The rise of digitalisation in agriculture is not only a technical issue, but it also has social, ethical and legal implications. Since the world of agriculture is quite diverse, it consists of different types of agricultural methods and farming realities. In order to maximize their potential, it is important that digital solutions are designed with a view to the farming communities' needs. This is especially true in African countries with very low literacy levels and limited knowledge of digital technologies, yet where the highest untapped agricultural potential remains. Farmers have concerns about issues around data ownership, access, and control, security, and privacy. Data asymmetries and imbalances as well as monopolies are quite present/dominant in the agricultural sector, these data asymmetries arise when smallholder farmers with rather limited resources reveal their most personal farm data to gain access to benefits of technology, while those who can transform the collected data into useful information reveal little to nothing about the back-end processes or how or where the information will be kept or used. Therefore, there is a need to address the question of the balance between the cost of introducing the technology versus the expected benefits for the farmers (Kritikos, 2017), Mostly in developing countries smallholder farmers are not harnessing the power of data and must overcome challenges and risks to ensure that investments benefit them. Farmers need to feel and be engaged in the decision process of how collectors will use their data. They also need assurances of their privacy and control, they seek transparency and trust in their interactions with providers, they would like to receive benefits of their data and to have access to relevant data, Codes of conduct in agriculture, voluntary guidelines, sets of principles on how to transparently govern farm data are a recent thing. These Codes have started to emerge to fill the legislative void and to set common standards for data sharing contracts: codes provide principles that the signatories/subscribers/members agree to apply in their contracts. Farm data is an example of such sensitive data flows. Farm data flows go from the farm to many other actors (extensionists/advisory service providers/agri-tech companies, farmers' associations, financial service providers, government...) and then - aggregated and combined and in the form of services - back to the farm. Such flows potentially open up data that should only be shared with specific actors at specific conditions or should be anonymised in order not to harm the farmer's interests and privacy. This is especially true in the case of smallholder farmers whose farm data often coincides with household data and personal data and who are in the weakest position to negotiate their data rights. We have also considered what such a code should cover to better empower farmers with more equitable data flows. We tried to draw some conclusions on commonalities and differences between the existing codes, guidelines and regulations, in order to then extract and recommend the essential aspects and points for a general, scalable and further customizable code of conduct template that best addresses the needs of the farmer, An interesting point from our farmeroriented perspective is that, the existing farm data codes do not have farmers or farmers' organisations as their primary target audience - not to mention smallholder farmers - but rather the agribusinesses and agri-tech companies that work with farmers and use their data. Codes are an instrument for these companies to ensure data sharing by gaining the trust of farmers through transparent documentation of good practices. So, while being prepared by bodies that represent also farmers (so far, big farmers' associations of developed countries) and indirectly raising farmers' awareness of their data rights, they are not written primarily for farmers and, so far, surely not for smallholder farmers. Therefore, from our perspective, during the Kampala INSPIRE Hackathon we have used another approach to our review of the current landscape from a further practical purpose: providing the conceptual basis for general scalable guidelines for associations of smallholder farmers in developing countries on how to use/adjust/ negotiate/set up a farmer-centered farm data sharing code.

\section{Developed SmartAfriHub platform and Open Source Softwares}

SmartAfriHub is a one of the Digital Innovation Hubs developed during Nairobi INSPIRE 
Hackathon 2019 and Kampala INSPIRE Hackathon 2020 - The intention was to support and further smart and sustainable agriculture and connect people to digital information and services in Africa. SmarAfrihub also integrates African agriculture and climate community members, and beyond, to the knowledge bases e.g., Blog, Forum, Science Shop, WIKI. DIH provides different types of Open Source Softwares and demo applications, where farmers, developers and researchers can cooperate, test different API for new solutions and also provide common experiments upon geospatial information and agriculture. SmartAfriHub is a part of SmartAgriHubs which is an EU project with more than 150 partners in the European agri-food sector, which aggregates and supports various innovation hubs. During Hackathon was discussed user interfaces, functionality and data availability.

SmartAfriHub (Figure 2) is built on the Liferay portal framework which provides a robust platform to build a website on quickly and serve it to all clients - desktop, mobile, or anything in between. It provides all the standard applications which are needed. It also provides an easy-to-use development framework for new applications or customization.

The high-level ambition of SmartAfriHub is to increase the number and quality of innovations in Africa smart agriculture to enhance sustainability. SmartAfriHub's purpose is to be a knowledge and technology platform that enhances knowledge transfer and exchange with and for Africa smart agriculture practitioners, experts and researchers. Kampala INSPIRE Hackathon showed how to raise awareness of the hub in Africa continent, how to use the hub in order to develop and share relevant content to subscribers, and how to encourage users to exploit the Open Source Softwares that are available on SmartAfriHub.

In order to demonstrate and monitor SmartAfriHub's results and impacts the following circumstantial evidence i.e., Key Performance Indicators (KPI) as applied (Table 1).

The experiences with hub demonstrated that it will take longer time to attract a large sustainable community and build a platform as long time sustentable.

In any case, a small community is using the SmartAfriHub tools and content on a regular basis, but for large scale extension will be necessary to commit considerable human and financial effort to attract an expansive scale community. The KPIs show on table 1 how the number of views and visitors on the platform reflects the number of new contents e.g., blogs and news. The awareness raising and building a social space requires social media presence. The Twitter tweets, Facebook and Linkedin postings amplify and share messages, and redirect the visitors to the SmartAfriHub.

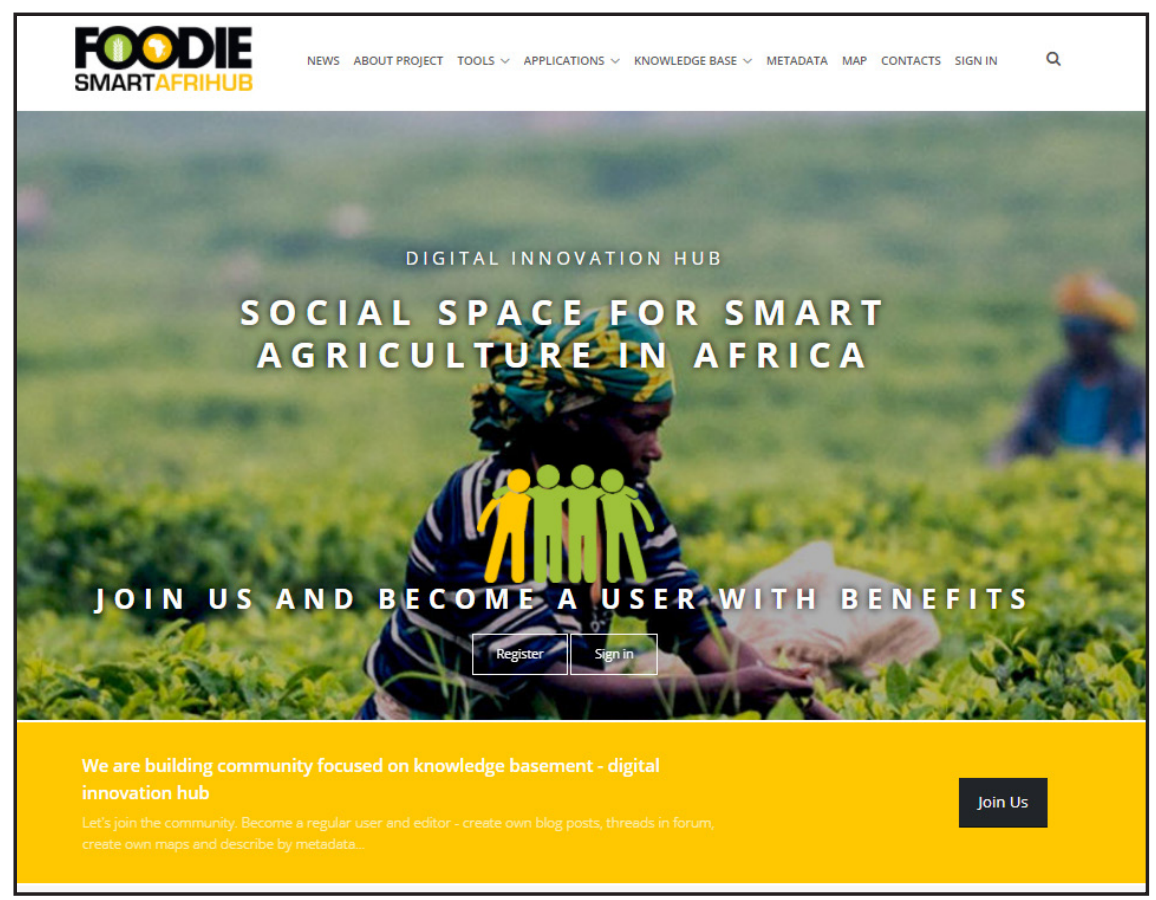

Source: SmartAfriHub, 2020

Figure 2: SmartAfriHub landing page. 


\begin{tabular}{|l|c|c|c|}
\hline Key Performance Indicators (KPI) & $\mathbf{1 . 2 . 2 0 2 0} \mathbf{- 3 1 . 3 . 2 0 2 0}$ & $\begin{array}{c}\mathbf{1 . 4 . - 3 1 . 5 . 2 0 2 0} \\
\text { Kampala INSPIRE Hackathon }\end{array}$ & $\mathbf{1 . 6 . 2 0 2 0}$-31.7.2020 \\
\hline Number of news/blogs & 2 & 68 & 13 \\
\hline Number of users & 82 & 1796 & 1268 \\
\hline Number of visits & 175 & 3474 & 3614 \\
\hline Number of page views & 641 & 10050 & 2629 \\
\hline Number of unique page views & 447 & 7414 & $44.27 \%$ \\
\hline Bouncerate & $56.26 \%$ & $37.04 \%$ & $00: 01: 34$ \\
\hline Visit duration & $00: 01: 42$ & $00: 02: 03$ & 5 tools \\
\hline $\begin{array}{l}\text { Number of OpenSource Software; } \\
\text { tools, applications }\end{array}$ & 4 tools & 8 applications & 8 applications \\
\hline Number of operative entities & 3 & 4 & 4 \\
\hline
\end{tabular}

Source: Google analytics

Table 1: Key Performance Indicators of SmartAfriHub (measuring: 2 months intervals).

The SmartAfriHub evolution has taken place in 2 waves i.e., in the context of hackathons.

\section{What is the best approach to build an active} community?

Community building is about reaching out to people, connecting them to each other and to upkeep dialogue. In cooperation with African colleagues, the non-African adopt local manners, also in the digital arena. The commonly used, widely achievable, an easy mobile application in Africa is WhatsApp. SmartAfriHub WhatsApp group of 50 people valued a low threshold approach to be part of the community: easy to join in, comfortable to use and it allows group members a free choice to act more or less actively.

Joining the WhatsApp group is only the first low threshold step in building a SmartAfriHub community. The common journey is about to start and the second step is ahead. The second step is addressed for those who have a desire and a need to utilize the advanced digital tools provided by SmartAfriHub platform. Being part of the community creates opportunities for continuous learning, development and also business. They provide value and satisfaction to members, create welfare and provide earnings.

Two Afica oriented INSPIRE Hackathons demonstrate needs for other support to adopt ICT technologies for African Agriculture. These solutions are necessary to guarantee food and nutrition security in Africa. we identified number of needs and gaps, which are important for future adoption and also needs for additional investment

As one of the main goals of African INSPIRE Hackathons and SmartAfriHub was to connect people to the information, tools and applications, the SmartAfriHub community and platform was (and still is) a place to inform community about upcoming or just aired webinars which were organized under the hackathon webinar series, but we also follow and promote webinars and other events that are organized by our Kampala INSPIRE Hackathon co-organizers GODAN, Research Data Alliance (RDA)/Agricultural Data Interest Group (IGAD), RCMRD, Ruforum and AfriGEO. Last but not least, SmartAfriHub News and Blogs helps us with the promotion of the existence, purpose, features, tools and applications of SmartAfriHub platform.

One clear goal is to increase the number of subscribers of SmartAfriHub. It could be done by using the active SmartAfriHub community on WhatsUp. In Africa, the number of social media users, particularly by mobile applications, is 172 million. The extending mobile phone network has opened the world also to remote rural areas. In order to reach out, connect and communicate with African agriculture practitioners and experts in urban and rural areas Whatsapp is the most powerful application today - "When in Rome, do as the Romans do". Although the webinars about SmartAfriHub gathered a lot of publicity, the number of the registered users and visits of SmartAfriHub didn't increase as much as expected, it's still too low and additional measures are needed. The team has learned that the social media promotion is not enough alone. We need a larger community and living ecosystem the members of which will gain true advantage of the use of SmartAfriHub and are willing to work with each other to enhance smart agriculture and a fair digital economy.

Build capacity by hands-on doing: The challenges aim was to facilitate the participants to develop 
their own maps by using the tools and applications. The lack of open agriculture data in Africa is an obvious problem in the process. Although we have tools, applications and know-how, our progress is limited by the lack of right kind of open data. We also learnt that the work-based learning by doing was difficult to carry out due the lack of adequate internet connection. Hence the necessary direction is to provide mobile based applications to agriculture experts.

Social space for learning and networking: We gathered a group of experts who are interested in developing smart agriculture in Africa. The group has participants from many African countries hence the diversity in problems, practices and possible development path is remarkable. The members proved to be active and goal oriented, and they put effort on finding suitable agricultural data and to test them by different applications.

There's evidence that the group members enjoyed the challenge, co-operation and co-creation. It was shown when they voluntarily and actively participated and contributed to progress and communication. It also seems that personal networks were extended both among African members and in the African - Europe dimension.

What is most positive feedback is that we simulate the initial community in Africa, which is able to support and introduce new technologies and the number of requests and needs and effort is coming from these communities. This was demonstrated after Kampala Hackathon on COVID 19 Hackathon

\section{Conclusion}

"The future of agriculture and forestry will rely on digitalisation and Digital Innovation Hubs and Hackathons can help with this process. It could become part of agriculture education, research, innovation actions should focus on digitalisation that supports FAIR, open and ethic data management and knowledge exchange. We need to identi means also that advisory and support organisations have both capacity and know-how to guide the farmers

Corresponding authors

Hana Kubičková

Plan4all z.s., K Rybnícku 33012, Horní Břiza, Czech Republic

Phone: +420608063 093,E-mail: hana.kubickova@plan4all.eu to uptake the applications and tools. Because knowledge and innovations are crucial in helping farmers and rural communities meet the challenges of today and tomorrow to enhance sustainability and prevent hunger, the enhancement of African system of Agricultural Innovation Hubs earns increasing attention.

This paper examined the interactions and effects of the concepts that are assumed to advance digitalization of African Food System (AFS). The 5 Concepts are Open Agricultural Data, OpenSource Software and Hardware, Citizen Science, privacy and legal and ethical issues, and the enabling Digital Innovation Hub (DIH) - SmartAfriHub (https://www.smartafrihub.com/home). In order to achieve a sustained AFS, there is a need to continue to develop an open data community in Africa where farmers have equal access to data to enhance productivity.

\section{Acknowledgments}

The SmartAfriHub was developed during the Nairobi INSPIRE hackathon 2019 and Kampala INSPIRE Hackathon 2020 and Dubrovnik INSPIRE Hackathon 2020, collaborative events organized by Plan4all, Club of Ossiach Associations, GODAN, FAO, IST-Africa Conference, Makerere University, Afrigeo, AfriAlliance, WirelessInfo, CSEOL and EU projects including EO4Agri, STARGATE, RDA Europe 4.0, SIEUSOIL, DEMETER, WeObserve, PoliRural, SmartAgriHubs, Next Génération of Global Earth Observation System of System (NextGEOSS), EUXDAT (European e-Infrastructure for Extreme Data Analytics in Sustainable Development), PoliVisu, and AfarCloud.

This research was funded by EO4Agri, grant number 821940 , STARGATE grant number 818187 , SIEUSOIL, grant number 818346, DEMETER grant number 857202, PoliRural, grant number 818496, EUXDAT grant number 777549, PoliVisu grant number 769608 and AfarCloud grant number 783221 ". 


\section{References}

[1] Addison, Ch. (2018) "Harnessing the benefits of data and farmer's data right to advance agriculture", The Technical Centre for Agriculture and Rural Cooperation (CTA) Blog. [Online] Available: https://www.cta.int/en/digitalisation/article/harnessing-the-benefits-of-data-and-farmers-data-right-to-advance-agriculture-sid03b328f73-9090-4396-9857-e2b1 ebf19659 [Accessed: 23 Sept. 2020].

[2] Afful-Dadzie, E. and Afful-Dadzie, A. (2017) "Open Government Data in Africa: A preference elicitation analysis of media practitioners", Government Information Quarterly, Vol. 34, No. 2, pp. 244-255. ISSN 0740-624X. DOI 10.1016/j.giq.2017.02.005.

[3] AfricaMe-Team (2020) "Agricultural data is becoming big business in Africa". [Online]. Available: http://africa-me.com/agricultural-data/ [Accessed: 13 Oct. 2020].

[4] African Development Bank (2020) [Online]. Available: https://www.afdb.org/ [Accessed: 9 Oct. 2020].

[5] Ahmed, A., Ghoneim, S. and Kim, R. (2009) "Knowledge management as an enabler of change and innovation in Africa", International Journal of Technology Management, Vol. 45, No. 1-2, pp. 10-26. E-ISSN 1741-5276, ISSN 0267-5730. DOI 10.1504/IJTM.2009.021517.

[6] Anand, S. (2020) "Kampala INSPIRE Hackathon 2020", F1000Research. DOI 10.7490/f1000research.1117838.1.

[7] Batchelor, S., Scott, N., Valverde, A., Manfre, C. and Edwards, D. (2014) "Is there a role for Mobiles to support Sustainable Agriculture in Africa?", Proceedings of the 2014 conference ICT for Sustainability, Advances in Computer Science Research. E-ISSN 2352-538X. DOI 10.2991/ict4s-14.2014.33.

[8] Bello, O., Akinwande, V., Jolayemi, O. and Ibrahim, A. (2016) "Open data portals in Africa: an analysis of open government data initiatives", African Journal of Library, Archives and Information Science, Vol. 26, No. 2, p. 97. E-ISSN 0795-4778.

[9] Bishwajit, G., Kota, K., Buh, A. and Yaya, S. (2020) "Self-Reported Food Insecurity and Depression among the Older Population in South Africa", Psych, Vol. 2, No. 1, pp. 34-43. E-ISSN 2624-8611. DOI 10.3390/psych2010004.

[10] Bye, B. L., Mildorf, T., Charvat, K. and Berre, A. J. (2017) "Hackathons as A Capacity Building Tool for Environmental Applications", American Geophysical Union, Fall Meeting 2017, abstract \#PA13E-07.

[11] Bye, B., Charvat, K., Mildorf, T. and Berre, A. J. (2018) "The INSPIRE Hackathons: A framework for solving real-life problems innovating with today's knowledge, data and technology", $20^{\text {th }} E G U$ General Assembly, EGU2018, Proceedings from the conference, 4-13 April, 2018 Vienna, Austria.

[12] Cerba, O. and Cerbova, K. (2013) "SDI, Communities, and Social Media", Czech Centre for Science and Society, pp. 1-6. ISBN 978-80-905151.

[13] CITI-SENSE (2016) "Development of sensor-based Citizens' Observatory Community for improving quality of life in cities". [Online]. Available: https://cordis.europa.eu/project/id/308524 [Accessed: 10 Sept. 2020].

[14] Clark, L., Higdon, G. L., Roberts, T., Barnett, I., Hernandez, K. and Martín, P. P. (2020) "Performance Evaluation of the Global Open Data for Agriculture and Nutrition Programme", In GODAN Performance Evaluation Final Report. [Online]. Available: https://iati.fcdo.gov.uk/iati documents/56313536.pdf [Accessed: 10 Sept. 2020].

[15] European Commission (2019) "Communication from the Commission to the European Parliament, the European Council, the Council, the European Economic and Social Committee and the Committee of the Regions", The European Green Deal. [Online]. Available: https://ec.europa. eu/info/sites/info/files/european-green-deal-communication_en.pdf [Accessed: 13 Oct. 2020]. 
[16] Copernicus (2020)" Europe's eyes on Earth". [Online]. Available: https://www.copernicus.eu/. [Accessed: 24 Oct. 2020].

[17] "COVID-19 INSPIRE Hackathon 2020". [Online]. Available: https://www.plan4all.eu/inspirehackathon/covid-19-inspire-hackathon-2020/ [Accessed: 24 Oct. 2020].

[18] Čerba, O. and Mildorf, T. (2016) "Smart points of interest: big, linked and harmonized spatial data", In EGU General Assembly Conference Abstracts.

[19] Dehnen-Schmutz, K., Foster, G. L., Owen, L. and Persello, S. (2016). Exploring the role of smartphone technology for citizen science in agriculture", Agronomy for Sustainable Development, Vol. 36, No. 25. E-ISSN 1773-0155, ISSN 1774-0746. DOI 10.1007/s13593-016-0359-9.

[20] European Union (2007) "Directive 2007/2/EC of the European Parliament and of the Council of 14 March 2007 establishing an Infrastructure for Spatial Information in the European Community (INSPIRE), Official Journal of the European Union. [Online] Available: https:/eur-lex.europa.eu/ legal-content/EN/TXT/PDF/?uri=CELEX:32007L0002\&from=EN [Accessed: 13 Oct. 2020].

[21] FAO (2018) "Sustainable food systems Concept and framework". [Online] Available: http://www.fao.org/3/ca2079en/CA2079EN.pdf [Accessed: 13.10.2020].

[22] Food Climate Research Network (FCRN) (2015) "A free and evolving resource to empower informed discussion on sustainable food systems", Chapter 1, Overview of food system Challenges. [Online] Available: https:/vdocuments.net/chapter-1-2015-2-foodsource-chapter-1-overview-of-foodsystem-challenges-contents.html [Accessed: 13 Oct. 2021].

[23] GEO (2020) "2020-2022 GEO Work Programme", Summary document. Version 4. [Online] Available: https://www.earthobservations.org/documents/gwp20_22/gwp2020_summary_ document.pdf [Acceseed: 1 Oct. 2020].

[24] Govender, L., Pillay, K., Siwela, M., Modi, A. and Mabhaudhi, T. (2017) "Food and Nutrition Insecurity in Selected Rural Communities of Kwazulu-Natal, South Africa-Linking Human Nutrition and Agriculture", International Journal of Environmental Research and Public Health, Vol. 14, No. 1, p. 17. DOI 10.3390/ijerph14010017.

[25] "Ground Truth 2.0". [Online] Available: https://gt20.eu/. [Accessed: 10 Oct. 2020].

[26] Harris, T. M. and Lafone, H. F. (2012) "Toward an informal Spatial Data Infrastructure: Voluntary Geographic Information, Neogeography, and the role of citizen sensors, in Kristyna Cerbova (ed) SDI, Communities, and Social Media, Vol. 8, pp. 8-12.

[27] Heidhues, F., Atsain, A., Nyangito, H., Padilla, M., Ghersi, G. and Vallée, L. (2004) "Development strategies and food and nutrition security in Africa: An assessment", Food Security and Poverty, 60 p. DOI 10.22004/AG.ECON.42270.

[28] Henriques, J. J. and Kock, B. E. (2012) "Empowering smallholders and local food markets with smartphones and social networks", 2012 IEEE Global Humanitarian Technology Conference, pp. 181-185. DOI 10.1109/GHTC.2012.37.

[29] Higgins, C. I., Williams, J., Leibovici, D. G., Simonis, I., Davis, M. J., Muldoon, C., van Genuchten, P., O’Hare, G. and Wiemann, S. (2016) "Citizen OBservatory WEB (COBWEB): A generic infrastructure platform to facilitate the collection of citizen science data for environmental monitoring", International Journal of Spatial Data Infrastructures Research. E-ISSN 1725-0463. DOI 10.2902/1725-0463.2016.11.art3.

[30] Charvát, K. (2009) "Future of Open Source systems", Geoinformatics FCE CTU, Vol. 4, pp. 45-54. ISSN 1802-2669. DOI 10.14311/gi.4.3.

[31] Charvat, K. and Krivanek, Z. (2010) "Dual licensing policy - New way for software development", IST-Africa 2010 Conference Proceedings, IEEE. ISBN 978-1-905824-15-1.

[32] Charvat, K., Esbri, M. A., Mayer, W., Campos, A., Palma, R. and Krivanek, Z. (2014b) "FOODIE - Open data for agriculture", In 2014 IST-Africa Conference Proceedings, IEEE. DOI 10.1109/ISTAFRICA.2014.6880647. 
[33] Charvat, K., Mildorf, T., Tuchyna, M., Vohnout, P., and Krivanek, Z. (2014a) "SDI4Apps", In 2014 IST-Africa Conference Proceedings, IEEE. DOI 10.1109/ISTAFRICA.2014.6880645.

[34] Charvát, K., Vohnout, P., Kafka, S. and Cepicky, J. (2011) "Social Space for Geospatial Information", In IST-Africa 2011 Conference Proceedings, IST-Africa. DOI 10.13140/RG.2.1.3595.2085.

[35] Jedlička, K., Mildorf, T., Charvát, K., Kozhukh, D., Charvát, K. Jr., Martolos, J. and Št’astný, J. (2015) "Benefits of Using Traffic Volumes Described on Examples in the Open Transport Net Project Pilot Regions", AGRIS on-line Papers in Economics and Informatics, Vol. 7, No. 2, pp. 39-46. ISSN 1804-1930. DOI 10.7160/aol.2015.070204.

[36] Jedlička, K., Hájek, P., Ježek, J., Kolovský, F., Mildorf, T., Charvát, K., Kozukh, D., Martolos, J., Št'astný, D. and Beran, D. (2016) "Open Transport Map: open, harmonized dataset or road network", In International Symposium on Computer-Assisted Cartography. AutoCarto.

[37] Jha, S., Kaechele, H., Lana, M., Amjath-Babu, T. S. and Sieber, S. (2020) "Exploring farmers' perceptions of agricultural technologies: a case study from Tanzania", Sustainability, Vol. 12, No. 3, p. 998. E-ISSN 2071-1050. DOI 10.3390/su12030998.

[38] Kamilaris, A., Kartakoullis, A. and Prenafeta-Boldú, F. X. (2017) "A review on the practice of big data analysis in agriculture", Computers and Electronics in Agriculture, Vol. 143, pp. 23-37. ISSN 0168-1699. DOI 10.1016/j.compag.2017.09.037.

[39] "Kampala INSPIRE Hackathon" (2020) [Online] Available: https://www.plan4all.eu/kampalainspire-hackathon-2020/ [Accessed: 13 Oct. 2020].

[40] Khaldoon, A., Hosseini, S. H. and Avery, H. (2020) "The Role of Citizen Science in Sustainable Agriculture", Sustainability, Vol. 12, No. 24, pp. 10375. E-ISSN 2071-1050. DOI $10.3390 /$ su122410375.

[41] Klerkx, L., Jakku, E. and Labarthe, P. (2019) "A review of social science on digital agriculture, smart farming and agriculture 4.0: New contributions and a future research agenda", NJAS-Wageningen Journal of Life Sciences, Vol. 90-91. ISSN 1573-5214. DOI 10.1016/j.njas.2019.100315.

[42] Kollwitz, C. and Dinter, B. (2019) "What the Hack?-Towards a Taxonomy of Hackathons", In International Conference on Business Process Management, Springer, Cham, pp. 354-369. DOI 10.1007/978-3-030-26619-6_23.

[43] Kritikos, M. (2017) "Precision agriculture in Europe: Legal, social and ethical considerations", study, Think Tank, European Parliament, Brüssel.

[44] Lynd, L. R. and Woods, J. (2011) "Perspective: A new hope for Africa", Nature, Vol. 474, pp. S20-S21. E-ISSN 1476-4687, ISSN 0028-0836. DOI 10.1038/474S020a.

[45] May, J., Karugia, J. and Ndokweni, M. (2007) "Information and Communication Technologies and Agricultural Development in Sub Saharan Africa: Transformation and Employment Generation". [Online]. Available: https://www.africaportal.org/publications/information-andcommunication-technologies-and-agricultural-development-in-sub-saharan-africa-transformationand-employment-generation/ [Accessed: 13 Oct. 2020].

[46] Mbow, C. (2020) "Use It Sustainably or Lose It! The Land Stakes in SDGs for Sub-Saharan Africa", Land, Vol. 9, No. 3, 63 p. E-ISSN 2073-445X. DOI 10.3390/land9030063.

[47] McCullough, E. B., Pingali, P. L. and Stamoulis, K. G. (Eds.) (2008) "The transformation of agri-food systems. Globalization, supply chains and smallholder farmers", Routledge, 408 p. ISBN 9781844075683.

[48] Middelberg, S. L. (2013) "Sustainable agriculture: A review of challenges facing the South African agricultural sector", Journal of Human Ecology, Vol. 42, No. 2, pp. 163-169. ISSN: 0970-9274. DOI 10.1080/09709274.2013.11906590.

[49] Mildorf, T., Charvát, K., Ježek, J., Templer, S. and Malewski, C. (2014) "Open Land Use Map", AGRIS on-line Papers in Economics and Informatics, Vol. 6, No. 4, pp. 81-88. ISSN 1804-1930. DOI 10.22004/ag.econ.196530. 
[50] Mkhize, M. and Sibanda, M. (2020) "A review of selected studies on the factors associated with the nutrition status of children under the age of five years in South Africa", International Journal of Environmental Research and Public Health, Vol. 17, No. 21, p. 79-73. E-ISSN 1660-4601. DOI 10.3390/ijerph17217973.

[51] Moorthy, I., Fritz, S., See, L. and McCallum, I. (2017) "LandSense: A citizen observatory and innovation marketplace for land use and land cover monitoring", $19^{\text {th }}$ EGU General Assembly, EGU2017, Proceedings from the conference, 23-28 April, 2017, Vienna, Austria.

[52] Musker, R. and Schaap, B. (2018) "Global Open Data in Agriculture and Nutrition (GODAN) initiative partner network analysis", F1000Research, Vol. 7, No. 47, p. 47. ISSN 2046-1402. DOI 10.12688/f1000research.13044.1.

[53] "Nairobi INSPIRE Hackathon" (2019). [Online]. Available: https://www.plan4all.eu/nairobi-inspirehackathon-2019/ [Accessed: 13 Oct. 2020].

[54] Navarro, M., Hernández, M. L., Marcsh, J. and Pérez, F. (2013) "INSPIRE and Social Empowerment for Environmental Sustainability Results from the HABITATS project", $2^{\text {nd }}$. ed., Project: Habitats - Social Validation of INSPIRE Annex III Data Structures in EU Habitats, TRAGSA Group. ISBN-13 978-84-616-3646-4. DOI 10.13140/2.1.4031.0720.

[55] Ndung'u, N. and Signé, L. (2020) "The Fourth Industrial Revolution and digitization will transform Africa into a global powerhouse", Foresight Africa 2020, pp. 61-73. [Online]. Available: https://www.brookings.edu/research/the-fourth-industrial-revolution-and-digitization-willtransform-africa-into-a-global-powerhouse/ [Accessed: 20 Oct. 2020].

[56] Ngcamu, B. S., and Chari, F. (2020) "Drought Influences on Food Insecurity in Africa: A Systematic Literature Review", International Journal of Environmental Research and Public Health, Vol. 17, No. 16. E-ISSN 1660-4601. DOI 10.3390/ijerph17165897.

[57] Nilsson, M., Griggs, D. and Visbeck, M. (2016) "Policy: map the interactions between Sustainable Development Goals", Nature News, Vol. 534, pp. 320-322. E-ISSN 1476-4687. ISSN 0028-0836. DOI $10.1038 / 534320 \mathrm{a}$.

[58] Paganini, N., Adinata, K., Buthelezi, N., Harris, D., Lemke, S., Luis, A., Koppelin, J., Karriem, A., Ncube, F., Nervi Aguire, E., Ramba, T., Raimundo, I., Selejmanovic, N., Swanby, H., Tevera, D.,... and Stöber, S. (2020) "Growing and Eating Food during the COVID-19 Pandemic: Farmers' Perspectives on Local Food System Resilience to Shocks in Southern Africa and Indonesia", Sustainability, Vol. 12, No. 20. E-ISSN 2071-1050. DOI 10.3390/su12208556.

[59] Rissola, G. and Sörvik, J. (2018) "Digital Innovation Hubs in Smart Specialisation Strategies", Publications Office of the European Union, Luxembourg. ISBN 978-92-79-94829-9. DOI $10.2760 / 575863$.

[60] Ryan, S. F., Adamson, N. L., Aktipis, A., Andersen, L. K., Austin, R., Barnes, L., Beasley, M. R., Bedell, K. D., Briggs, S., Chapman, B., Cooper, C. B., Corn, J. O., Creamer, N. G., Delborne, J. A., Domenico, P., Dricoll, E., Goodwin, J., Hjarding, A., Hulbert, J., M., Isard, S., Just, M. G., Kar Gupta, K., López-Uribe, M. M., O’Sullivan, J., Landis, E. A., Madden, A. A., McKenney, E. A., Nichols, L. M., Reading, B. J., Russel, S., Sengupta, N., Shapiro, L. R., Shell, L. K., Sheard, J. K., Shoemaker, D. D., Sorger, D. M., Starling, C., Thakur, S., Vatsavai, R. R., Weinstein, M., Winfrey, P., ... and Dunn, R. R. (2018) "The role of citizen science in addressing grand challenges in food and agriculture research", Proceedings of the Royal Society B, Vol. 285, No. 1891, ISSN 2018-1977. DOI 10.1098/rspb.2018.1977.

[61] Shao, D. D. and Saxena, S. (2019) "Barriers to open government data (OGD) initiative in Tanzania: Stakeholders' perspectives", Growth and Change, Vol. 50, No. 1, pp. 470-485. E-ISSN 1468-2257. DOI 10.1111/grow.12282.

[62] SmartAfriHub [Online]. Available: https://www.smartafrihub.com/home [Accessed: 10 Oct. 2020]. 
[63] Thompson, H. E., Berrang-Ford, L. and Ford, J.D. (2010) "Climate change and food security in sub-Saharan Africa: a systematic literature review", Sustainability, Vol. 2, No. 8, pp. 2719-2733. E-ISSN 2071-1050. DOI 10.3390/su2082719.

[64] Tonnang, H. E., Guimapi, R. A., Bruce, A. Y., Makumbi, D., Mudereri, B. T., Balemi, T. and Craufurd, P. (2020) "PPMaP: Reproducible and Extensible Open-Source Software for Plant Phenological Phase Duration Prediction and Mapping in Sub-Saharan Africa", Agriculture, Vol. 10, No. 11. E-ISSN 2077-0472. DOI 10.3390/agriculture10110515.

[65] Ulman, M., Šimek, P., Masner, J., Kogut, P., Löytty, T., Crehan, P., Charvát, K., Oliva, A., Bergheim, S. R., Kalaš, M., Kolokol, D. and Sabbatini, T. (2020) "Towards Future Oriented Collaborative Policy Development for Rural Areas and People", AGRIS on-line Papers in Economics and Informatics, Vol. 12, No. 1, pp. 111-124. ISSN 1804-1930. DOI 10.7160/aol.2020.120110.

[66] Wanyama, R., Gödecke, T. and Qaim, M. (2019) "Food security and dietary quality in African slums", Sustainability, Vol. 11, No. 21, p, 5999. E-ISSN 2071-1050. DOI 10.3390/su11215999.

[67] Wong, M., Levett, K., Box, P., Simons, B., Thompson, H., Macleod, A., David, R., Schneider, D., Watkins, D., Hergenhan, R., Gregory, L., Wilson, P., Taylor, N., Limmer, S., Gillet, H. and Cox, S. (2019) "Implementing FAIR in the Agricultural Research Federation, Austraila", In eResearch Australasia Conference, Brisbane, Australia, 21 - 25 October 2019.

[68] Zampati, F. (2019) "Codes of conduct: providing an ethical approach to big data in agriculture", The Technical Centre for Agriculture and Rural Cooperation (CTA), Spore, [Online]. Available: https://spore.cta.int/en/opinions/article/codes-of-conduct-providing-an-ethical-approach-to-bigdata-in-agriculture-sid0700a1b64-6f93-4c70-aa77-186c152b2b1d [Accessed: 10 Oct. 2020]. 